\title{
Natural gas hydrates vs. induced dysfunctions in the hydrocarbon extraction process
}

\author{
Diana-Andreea Lupu ${ }^{1,}$, and Dan-Paul Stefanescu ${ }^{2}$ \\ ${ }^{1}$ Lucian Blaga University of Sibiu, Faculty of Engineering, Department of Industrial Engineering and \\ Management, Sibiu, Str. Emil Cioran nr.4 \\ ${ }^{2}$ Lucian Blaga University of Sibiu, Faculty of Engineering, Department of Industrial Engineering and \\ Management, Sibiu, Str. Emil Cioran nr.4
}

\begin{abstract}
Cantoned fluids in porous-permeable or fractured media of reservoirs have acquired during the geological time special properties. The fluids from the reservoir could be or not a mixture of reservoir water, liquid hydrocarbons and gaseous hydrocarbons. Considering if inside of a reservoir there are two types of substances like natural gas and reservoir water which may be in the form of vaporous than the condition of saturation of gases with water vaporous is fulfilled. This process is taking place due to thermodynamic equilibrium resulting the so-called gas humidity. This state corroborated with a certain chemical composition plus favourable values of pressure and temperature may be decisive in the appearance of hydrates. In this scientific paper they will be presented from a theoretical and practical point of view the favourable conditions of gas hydrates appearance and the specific ways of inhibiting the formation of this compounds. A case study in which through modelling and numerical simulation of the behaviour of a productive natural gas well will provide a series of data related to this phenomenon. The specific modelling and numerical simulation was adapted to the conditions of formation and subsequently the elimination of the appearance of hydrates.
\end{abstract}

\section{Introduction aspects related to natural gas impurities}

It is known that natural gases are a mixture of both hydrocarbons, which are in a certain proportion, and other substances from the so called category of chemical or mechanical impurities. Impurities can be natural impurities or resulting after applying specific procedures for stimulating the gas field productivity. The most common natural impurities are water in form of vapour, nitrogen, carbon dioxide and hydrogen sulphide.

There are frequent situations connected with the fact that gaseous hydrocarbon reservoirs (fields) are adjacent to large water saturated areas called aquifers and that is why natural gases are saturated with water and thus acquiring a certain humidity.

Humidity is influenced by the composition of the gases and by the pressure and the temperature of the system (eg: gas reservoir, pipeline section etc). For information it is specified the fact that acid gases, so those that contain $\mathrm{H} 2 \mathrm{~S}$ and $\mathrm{CO}_{2}$, have a bigger

* Corresponding author: diana.lupu@ulbsibiu.ro 
humidity, at the same pressure and temperature conditions, in comparison with natural gases at which the percentage of methane exceeds $70 \%$.

For these gases where methane is predominant, alongside with small percentage of heavy hydrocarbons, mixture known under the name of dry gases, the diagram from Fig. 1 is useful both for establishing the humidity of these types of gases as well as the approximate delimitation of the formation domain of the cryohydrates. It is to be specified the fact that this diagram was published in 1958 and based on impressive number of scientific research. This diagram is useful both in designing specific separation and gas drying units as well as in the process of producing these hydrocarbons.

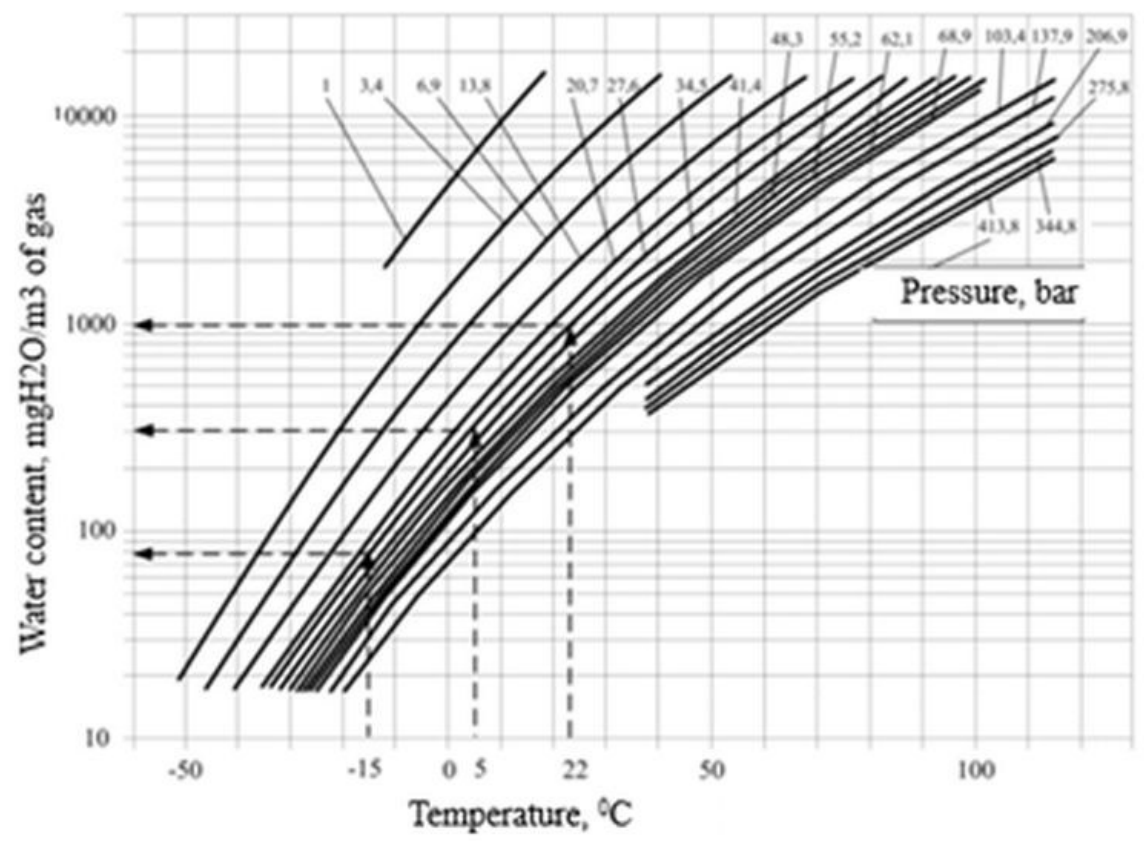

Fig. 1. Water content diagram [1]

It can be seen that the mentioned diagram allows the correction of the values belonging to water content in gas taking into account the water salinity and relative gas density.

The water content of gases can also be determined by use some methods which are known in the international specialized literature under the name of "Valve Freeze Method", "Bureau of Dew Point Tester", or "Cobalt Bromide Method". The last-mentioned method allows to determine the water content of dry gas until $25-30 \mathrm{mg} / \mathrm{kg}$. Below this range, more precisely under $20 \mathrm{mg} / \mathrm{kg}$, and in the adjacent of a dew point around $-40^{\circ} \mathrm{C}$, which is otherwise achievable for those drying units where solid desiccants are used (eg : silica gel), leads to obtain a very high purity of natural gas. Obtaining such an extremely low water content in gas, content which is called gas humidity, no longer represents a priority from a technological point of view for deductible reasons.

Therefore, the liquid impurities which in aqueous phase, are those who give the dimension of the water content in gas or in other words the humidity of the gas. If to this state is added a certain chemical gas composition which in turn is correlated with favourable temperatures and pressures from the system then the appearance of the solid substances similar with snow may be possible. These substances are called cryohydrates or 
natural gas hydrates and they have a low stability. Cryohydrates burn and the residue is water.

\section{Proper conditions for forming the cryohydrates}

The appearance of the cryohydrates is of physical nature. Chemical bonds between hydrocarbons and water are weak and that is why the stability of this compounds is low.

In 1810 the British chemist Davy Humphray identified the first gas cryohydrate. Much later, in France, in 1888, has been highlighted the cryohydrate of methane, and that of ethane in 1890 both of them by the researcher F.Villard. Besides these two cryohydrates have been identified cryohydrates of propane, n-butane and iso-butane. Subsequent research has revealed the fact that other gases, such as chlorine, carbon dioxide, hydrogen sulphide etc in presence of water can form such combinations.

Cryohydrates have a crystalline structure being composed for the most part from water molecules. and the spaces between these molecules can be occupied by the hydrocarbon molecules. "Studies performed with the help of the analysis of nuclear magnetic resonance spectra and dielectric adsorption spectra showed that hydrocarbon molecules rotate freely into the spaces of crystallin network" [2].

Relevant researches and connected with the idea above mentioned has been done by W.F.Clausen and V.Stackelberg who, independently of each other, demonstrated that the cryohydrates crystalline grid consist both of water molecules and spherical empty spaces .Inside of this empty spaces there are gas molecules in motion. Experimental results demonstrated that two different cryohydrate crystalline grids exist and whose brief presentation is as follows:

a. A first structure which from the geometrically point of view has a dodecahedral shape is made up of water molecules and between the spaces of these molecules enter methane molecules. Dimensionally speaking this structure is a small one and corresponds to the proportion of 5 and 3/4 water molecules at one gas molecule.

b. The second structure corresponds, geometrically speaking, to the hexa-dodecahedral configuration and has much more larger spaces fact for which bigger molecules than methane such as iso-butane even normal-butane may be included. From the dimensional point of view such a structure consists of 17 water molecules and one gas molecule.

The mechanism of cryohydrates formation is a complex one and consists of following phases: the saturation of gases with water vapour and then followed by vapour condensation and the appearance of free water which is separated from the gas flow and accumulate in different area of the interior productive infrastructure(eg: christmas tree, pipe lines etc), initiation of crystallization, in the presence of favourable pressure and temperature values, followed by in fact crystallization and having as a consequence the appearance of cryohydrates with different stability degrees [3].

Each cryohydrate is formed in different pressure and temperature conditions and associated to specific gas compositions. To these conditions is added an essential one ,namely the one related to existence of free water into the medium/space of hydrates forming. Regarding to the necessity of free water presence like on essential condition for hydrates forming the opinions of specialists in this domain are divided in the sense that is sustained the hypothesis according to which cryohydrates can be formed in case of coexistence of gases with water vapour, the latter influencing the gas humidity. This hypothesis has not been confirmed in practice. It is worth mentioning the fact that small amounts of ethane or propane which are in natural gases flux reduce drastically the pressure of cryohydrates formation in comparison with the situation of non-existing of these two substances (Fig.2). 


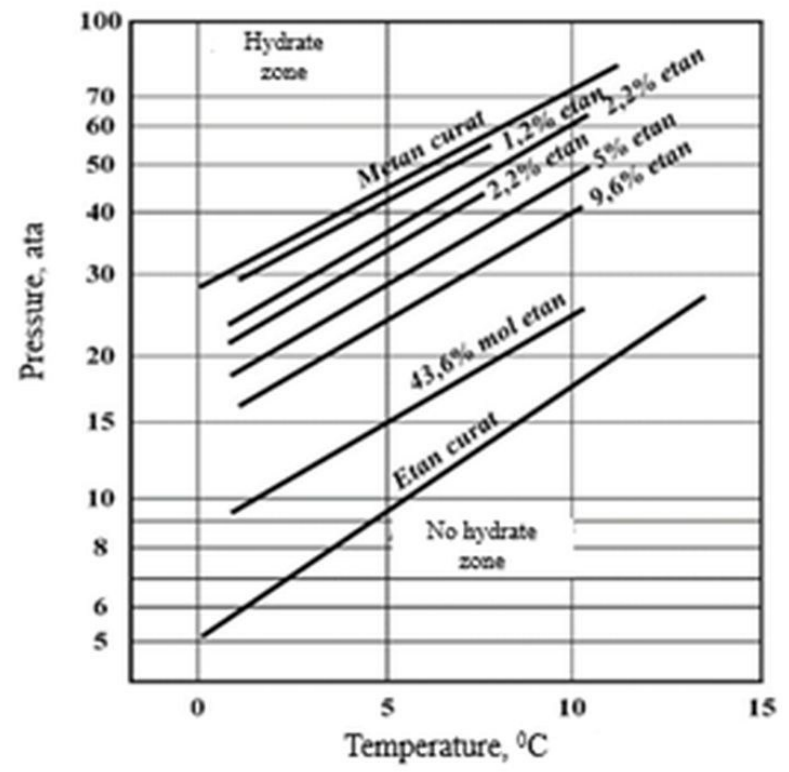

Fig. 2. The conditions for the formation of cryohydrates of a methane-ethane mixture [4]

This is the reason why ethane and propane must be eliminated from the natural gases flow which is transported through the pipeline system. Continuing the idea, it is noticed the fact that these small added amounts modify the density of natural gas in the sense of its increment and this is the reason why the cryohydrates are stable at higher temperature and low pressure.

The density of cryohydrate crystals varies between the limits of $880-900 \mathrm{~kg} / \mathrm{cm}$ thus floating on the water which is inside of pipelines. When the temperature rises or the pressure decreases the crystals decompose in water and gaseous hydrocarbons. For each simple cryohydrate exists a superior limit compatible with its formation and after this limit, regardless of pressure, the cryohydrate can no longer arise. These temperature values are as follows: for methane $21.5{ }^{\circ} \mathrm{C}$, for ethane $14,5{ }^{\circ} \mathrm{C}$ and for propane $5,5{ }^{\circ} \mathrm{C}$. The cryohydrates formation pressure decreases with mass molecular increasing. It is mentioned that after many field observations corroborated with the diagrams of phase equilibrium it was found that for the natural gas cryohydrates once formatted and existing, for instance at the temperature of $5{ }^{0} \mathrm{C}$, these are stabile at the following pressure values; for methane cryohydrate, $\mathrm{p}=45$ bar, for ethane cryohydrate, $\mathrm{p}=9$ bar, and for the one of propane, $\mathrm{p}=4,5$ bar.

Estimating the temperature and pressure values associated to cryohydrates formation it can be done with the help of same simple calculation methods, but not very accurate in comparison with the experimental researches which are specific for each case. Thus for the calculation of the natural gas cryohydrates formation conditions Hammerschmidt proposed the following relationship [4]:

$$
t=10.6 \cdot P^{0.285}-17.8
$$

where $t, p$ represent the temperature (in Celsius degrees), and the pressure (in bar), of cryohydrates forming, respectively. 
Another method of estimation the conditions of cryohydrates formation was elaborated by the American scientists Wilcox W.I., Carson D.B. and Katz D.L., who issued the hypothesis, otherwise plausible, according to which gas cryohydrates behave, to some extent, as mixture composed of gases and solid crystals. In this way an analogy could be made between liquid-vapour equilibrium states with vapour-solid equilibrium states thus being able to establish with the help of vapour -solid equilibrium constants the conditions of cryohydrates formation.

The expression of the equilibrium constants is of the form:

$$
k_{w}=\frac{y}{x_{s}}
$$

Where:

$y-$ molecular fraction of hydrocarbons in gaseous phase saturated with water vapour,

$\mathrm{x}$ - hydrocarbons fraction in cryohydrate.

The equilibrium constants depend on both pressure and temperature and gas composition. The initial formation conditions of cryohydrates are calculable with the following relationship:

$$
\sum \frac{y}{k_{r-s}}
$$

If the value obtained from relationship (3) is smaller than 1 this means that cryohydrates does not form, and if the value obtained from the relationship is very close to 1 the crystallization process implicitly the cryohydrates formation is possible.

\section{Applicable methods regarding the prevention of the appearance of cryohydrates in the gas extraction and transport process}

The dysfunctions related to the formation and maintenance of the stability of cryohydrates are related both to the decrease of the gas flow, in a first stage, to later to stop the gas flow in different areas of the production system. Finding the moment when the formation of cryohydrates begins, before their priming and stabilization begins, is of great importance as it is known that the beginning of hydrate formation is one specific to the conditions of pressure, temperature and composition of natural gas.

Over the years, it has been found on the basis of numerous laboratory and / or site experiments that the presence of variables, phenomena and reactions changes the conditions of formation, development and stabilization of cryohydrates. In this sense, mechanical and physico-chemical techniques have been developed in order to prevent the formation of cryohydrates or to combat the problems caused by them in the natural gas production system.

Preventive hydration techniques are mainly based on the following:

- Decreased gas pressure below the equilibrium pressure of hydrates, decrease correlated with temperature conditions. This can be done by using deep and / or surface nozzles whose diameters provide that equilibrium pressure at which no cryohydrates are formed.

- Increasing the temperature of the gas by heating at a temperature higher than the equilibrium, at a given dynamic pressure. This technique involves the use of natural gas heaters in the vicinity of the eruption heads, and if the route of the supply pipes extends a long distance, the pipes in the collector network must be made of high-strength steel and protected from the outside.

- Adding in the gas flow some chemicals with inhibitory role. Inhibitors are readily soluble in water as opposed to substances that give rise to cryohydrates. Methanol and alcohols are mainly used. Sodium chloride $(\mathrm{NaCl})$ and calcium chloride $(\mathrm{CaCl} 2)$ can also 
be used. These chemicals are also called "thermodynamic inhibitors" because they prevent the chemical reaction between gaseous hydrocarbons and water vapour and have an effect on the formation curve of cryohydrates in the sense of its movement in the region where cryohydrates are not formed. Methanol $\left(\mathrm{CH}_{3} \mathrm{OH}\right)$ is the most widely used chemical due to its advantages, namely: relatively low acquisition and operating cost, low viscosity, low solubility in liquid hydrocarbons and low vaporization pressure. The amount of methanol that serves as an inhibitor usually ranges from $0.25-1$ liters / Nm3 of gas. The dosage is based on the manufacturer's instructions depending on the methanol concentration, as well as the gas pressure and temperature. [5]

The process of selecting a preventive method involves performing a comparative analysis in which a number of factors are evaluated, such as: operating cost, safety, efficiency, and in the case of chemicals (eg glycols) is also concerned their regeneration or recovery.

\section{Case study - determination of hydrate formation conditions. Simulation of the behaviour in operation of a well from the Moesian platform}

The well belongs to a commercial natural gas field located in Dâmbovița County, and from a geological point of view it is located at the northeastern extremity of the Moesic Platform. In 2017, the well opened a sandy sequence of Meotian age, and during operation in the cold season (winter 2017-2018) problems were found related to the operation of the well due to the appearance of hydrates in the production system (see Fig. 3)

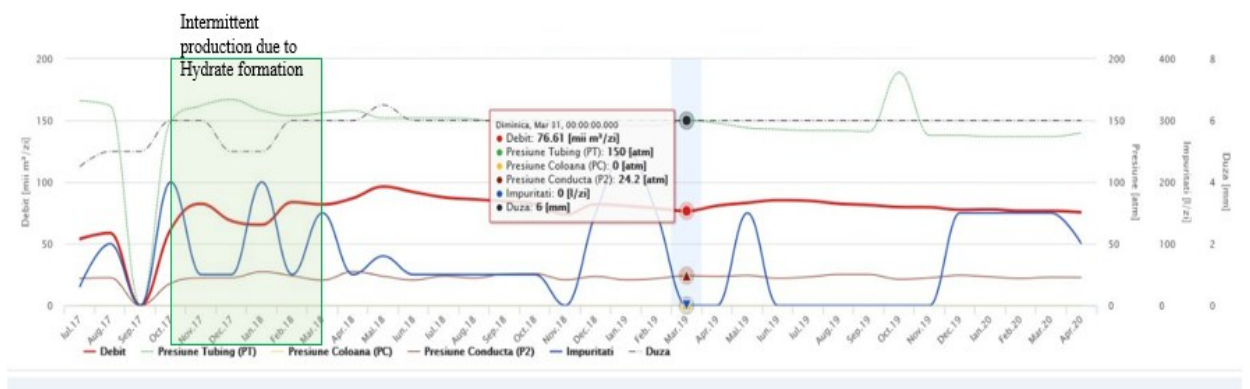

Fig. 3. Natural gas well production history

As it can observe in the fig. 3 the gas production rate (red line) in the marked areaintermittent production due to hydrate formation-is unstable due to the blockages created inside the tubing and into the surface flow line (field pressure is fluctuating)

In order to determine the cryohydrate formation conditions, the production parameters related to the well were centralized in Table 1.

Table 1. Production parameters of the natural gas well

\begin{tabular}{|l|c|l|}
\hline Production parameters & Value & \multicolumn{1}{|c|}{ Observation } \\
\hline Choke size (mm) & 6 & From daily reports \\
\hline P1 (bar)- pressure before choke & 148 & average \\
\hline P2 (bar)- field pressure & 22 & average \\
\hline$P_{\text {tubing }}$ (bar) (PT) & 158 & average \\
\hline
\end{tabular}




\begin{tabular}{|l|c|l|}
$\mathrm{P}_{\text {casing }}$ (bar) (PC) & 0 & Equipped with filter-packer assembly \\
\hline Daily gas rate (kstm3/d) & 83 & average \\
\hline Daily water rate (mc/d) & 0.1 & average \\
\hline Water-gas ratio (m3/stm3) WGR & 1.25 e-6 & average \\
\hline
\end{tabular}

In the first stage, the hydrate formation conditions were determined, and subsequently, the optimal operating conditions of the well were simulated for which there is no risk of hydrate formation in the production system.

\subsection{Determination of cryohydrate formation conditions}

a) The moisture content of the gases was determined. At the reservoir pressure $p=188.2$ bar and the reservoir temperature $\mathrm{T}=50{ }^{\circ} \mathrm{C}$, the gas humidity determined from the nomogram "Moisture content of natural gas at different pressures and temperatures" [6] is $0.3 \mathrm{~g} / \mathrm{nm} 3 \mathrm{gas}$. In this context, if the well is operated on a $6 \mathrm{~mm}$ choke size, and the gas flow is $83 \mathrm{kscm} /$ day, the water content is approx. $201 /$ day.

b) The critical temperature zone at which there is a risk of cryohydrate formation has been determined. Based on the production history of the well and using the relation (1) it turned out that under the current operating conditions $(\mathrm{PT}=158$ bar), the critical temperature is $16^{\circ} \mathrm{C}$.

c) Determining the equilibrium diagram for the methane-water-cryohydrate system for the natural gas well in the thermodynamic modelling program.

Input parameters in the creation of the well model are presented in Table 2.

Table 2. Input parameters in creating the well model

\begin{tabular}{|l|c|}
\hline Well construction data & $1993 \mathrm{~m}$ \\
\hline Well depth & $1993 \mathrm{~m}$ \\
\hline Top of cement & $5 \frac{1 / 2}{}{ }^{\prime} \times 1994 \mathrm{~m}$ \\
\hline Casing (exploitation) & $27 / 8^{\prime} \times 1942,78 \mathrm{~m}$ \\
\hline Tubing (R N80) & $1986-1993 \mathrm{~m}$ \\
\hline Reservoir data & gas + water \\
\hline Perforated interval & 201 \\
\hline Fluids & 188,2 \\
\hline Initial reservor pressure (bar) & 177,6 \\
\hline Actual reservoir pressure (bar) & 50 \\
\hline Bottomhole flowing pressure (bar) & 4 \\
\hline Reservoir temperature ( $\left.{ }^{0} \mathrm{C}\right)$ & \\
\hline Reservoir thickness $(\mathrm{m})$ & \\
\hline
\end{tabular}

\section{Reservoir description, selection of IPR model (production system performance curve) and data calibration}

The analysis used the IPR PI (Productivity Index) flow model and calibrated the flow using the Gray modified equation [7], an equation suitable for vertical wells exploiting dry gas reservoirs, in which the methane content is over $92 \%$. For calibration, the data from the field measurements in dynamic regime (choke size $6 \mathrm{~mm}$ ), bottom hole flowing pressure, $\mathrm{Pdf}=177$ bar were considered. In fig. 4 shows the IPR model related to well.

Nodal analysis in order to determine the flow behaviour of the well in different operating regimes 
Dynamic field measurement was performed when the well was produced on the $6 \mathrm{~mm}$ choke size which is why it was admitted that the dynamic pressure is representative for that moment, and after a good calibration of the field data with the model was obtained, a nodal sensitivity analysis was performed on different choke sizes to determine the productive behaviour of the well, illustrated in table 3 .

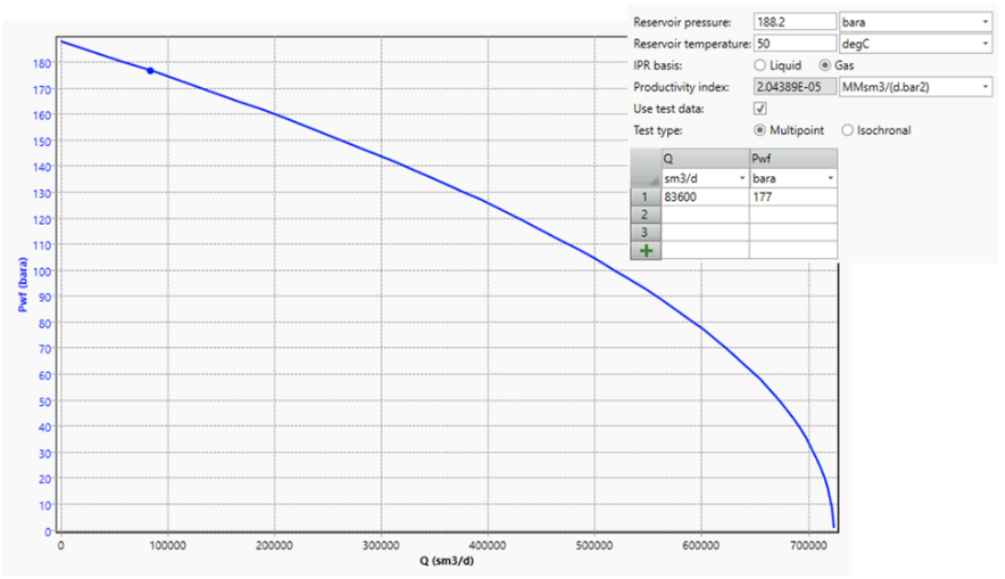

Fig. 4. IPR curve of well (Productivity Index)

Table 3. The results of the sensitivity nodal analysis for analysed well

\begin{tabular}{|c|c|c|}
\hline Choke size $[\mathrm{mm}]$ & $\begin{array}{c}\text { Bottomhole flowing } \\
\text { pressure [bara] }\end{array}$ & Gas rate [stcm/day] \\
\hline 4 & 184.23 & 30212.69 \\
\hline 5 & 182.07 & 46377.55 \\
\hline 6 & 179.60 & 64640.17 \\
\hline 7 & 176.91 & 84247.30 \\
\hline 8 & 174.13 & 104181.60 \\
\hline 10 & 168.77 & 141729.50 \\
\hline 12 & 164.35 & 171829.30 \\
\hline 14 & 161.15 & 193155.10 \\
\hline
\end{tabular}

The composition of the fluid expressed in molar fractions for the generation of the equilibrium diagram is shown in fig. 5. In the absence of a PVT analysis, the gas composition determined by the gas-chromatograph analysis was considered representative and relevant in the simulation. 


\begin{tabular}{|c|c|c|c|c|c|c|c|c|}
\hline Composition & density $(\mathbf{1 a t m}, \mathbf{1 5} \mathbf{~ d e g ~ C )}$ & $\mathbf{M}$ & Vol & Vol & Mass & Mass & Mole & Mole \\
\hline & $\mathrm{kg} / \mathrm{m3}$ & $\mathrm{kg} / \mathrm{kmol}$ & fraction & $\%$ & fraction & $\%$ & fraction & $\%$ \\
\hline methane & 0.693 & 16.043 & 0.99720 & 99.720 & 0.67862 & 67.862 & 0.91520 & 91.520 \\
\hline etane & 1.262 & 30.07 & 0.00070 & 0.070 & 0.00087 & 0.087 & 0.00062 & 0.062 \\
\hline propane & 1.875 & 44.1 & 0.00040 & 0.040 & 0.00074 & 0.074 & 0.00036 & 0.036 \\
\hline iso-butane & 2.51 & 58.12 & 0.00010 & 0.010 & 0.00025 & 0.025 & 0.00009 & 0.009 \\
\hline butane & NA & NA & 0.00000 & 0.000 & 0.00000 & 0.000 & 0.00000 & 0.000 \\
\hline iso-pentane & 616 & 72.15 & 0.00010 & 0.010 & 0.06049 & 6.049 & 0.01814 & 1.814 \\
\hline pentane & NA & NA & 0.00000 & 0.000 & 0.00000 & 0.000 & 0.00000 & 0.000 \\
\hline hexane & 655 & 86.18 & 0.00040 & 0.040 & 0.25728 & 25.728 & 0.06459 & 6.459 \\
\hline nitrogen & 1.185 & 28 & 0.00040 & 0.040 & 0.00047 & 0.047 & 0.00036 & 0.036 \\
\hline carbon dioxide & 1.8727 & 44.01 & 0.00070 & 0.070 & 0.00129 & 0.129 & 0.00063 & 0.063 \\
\hline Total & NA & NA & $\mathbf{1 . 0 0}$ & $\mathbf{1 0 0 . 0 0}$ & $\mathbf{1 . 0 0}$ & $\mathbf{1 0 0 . 0 0}$ & $\mathbf{1 . 0 0}$ & $\mathbf{1 0 0 . 0 0}$ \\
\hline
\end{tabular}

Fig. 5. Gas composition determined by the gas-chromatograph analysis

Defining the separation conditions (flash) at the separator and generating the equilibrium diagram of the gas-water-hydrate system related to well. The separation conditions, respectively the phase composition, were calibrated in the simulator at standard conditions, after which an adjustment was made to the composition with the pressure measured at the separator ( 22 bar). This resulted in the equilibrium diagram of the gaswater-hydrate system specific to well, diagram illustrated in Fig.6.

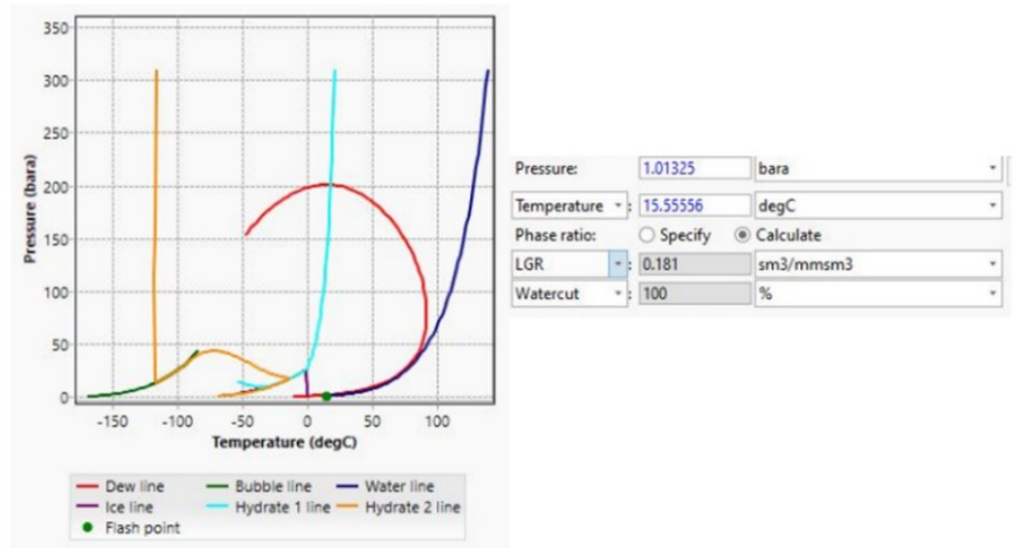

Fig. 6. Equilibrium diagram of the methane-water-hydrate system of the well.

Fig.6 shows the allure of specific methane-water-hydrate equilibrium diagram for the well indicate that the system under the current exploitation condition, where the pressure at separator is 22 bar and the liquid-gas ratio (LGR) is $0.181 \mathrm{sm} 3 / \mathrm{mil} . \mathrm{stm} 3$, taking into account the gas composition defined in fig.5.

\subsection{Simulation of the gas well behaviour without the risk of cryohydrate formation}

The simulation of the operating conditions of well without the occurrence of the risk of formation of cryohydrates consisted in completing the following steps:

a) The pressure-temperature profile $(P-T)$ vs. depth was generated in the production system related to well, from the reservoir to the separator according to fig. 7 . 


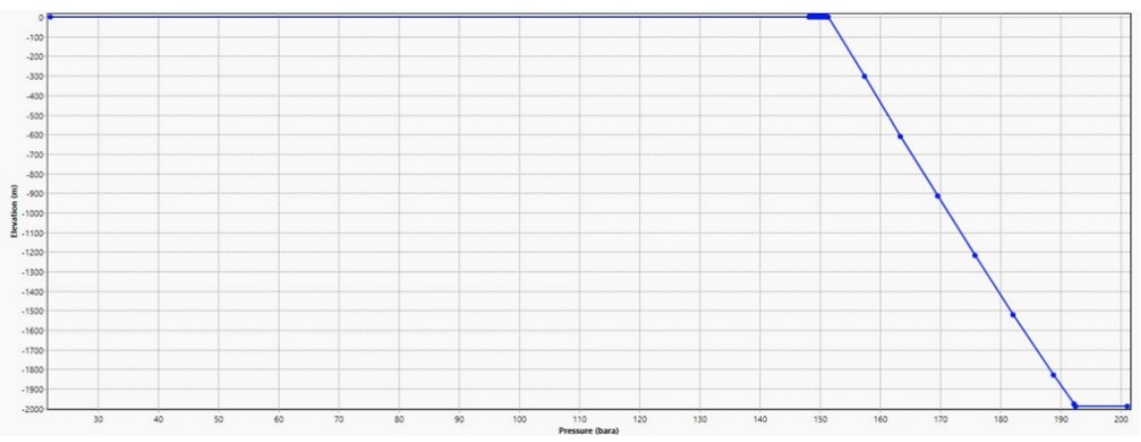

Fig.7. Pressure-Temperature profile vs.depth

b) Overlap of the pressure-temperature profile vs.depth over the methane-water-hydrate equilibrium diagram corresponding to the well. As shown in fig.8, under these operating conditions, the risk of formation of cryohydrates occurs in the vicinity of the christmas tree, where the gas temperature is $14^{0} \mathrm{C}$.

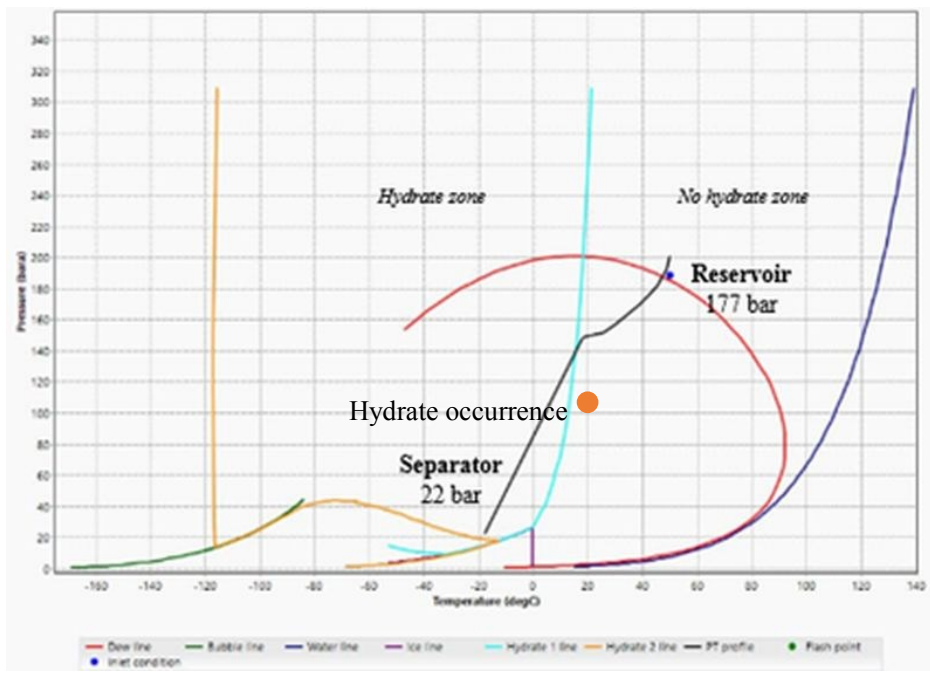

Fig. 8. Methane-water-hydrate equilibrium diagram for well over which the P-T profile vs.depth is overlap (choke size $\Phi 6 \mathrm{~mm}$ )

Knowing the conditions of dynamic flow pressure for different operating regimes, a simulation was performed from the perspective of the behaviour of the well on the same methane-water-hydrate equilibrium diagram and it has determined that if the well is produce on choke size of $12 \mathrm{~mm}$ the operation will be out of the hydrate zone, as shown in fig.9. 


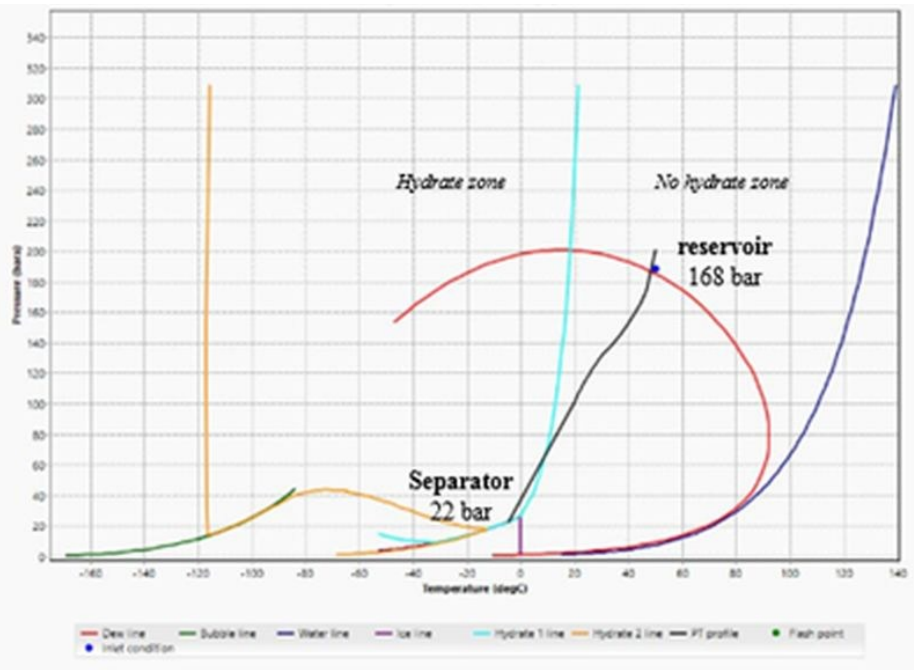

Fig. 9. Methane-water-hydrate equilibrium diagram for well over which the P-T profile is overlap (choke size $\Phi 12 \mathrm{~mm}$ )

\section{Conclusions}

Based on the simulation results, it can be concluded as follows:

1. The critical gas temperature must be higher than $16^{\circ} \mathrm{C}$ for the operation of the natural gas well to be outside the cryohydrate formation area, taking into account the dynamic pressure of 158 bar.

2. Calibration of the well model was performed based on production tests with choke size of $\Phi 6 \mathrm{~mm}$, the IPR Productivity Index model and the Gray modified flow equation were used, an equation suitable for vertical well that produce dry gas. The results obtained during the sensitivity nodal analysis (bottomhole flowing pressure and gas rates) -where the choke size diameter was the variable parameter- were used to simulate the behaviour of the well in different circumstances of regime exploitation in order to determine the optimal choke size to avoid hydrates formation.

3. By overlapping the Pressure-Temperature profile vs.depth related to the reservoirsurface (separator) system with the same methane-water-hydrate equilibrium diagram, different exploitation scenarios were simulated, which resulted in the fact that at bottomhole flowing pressure (Pdf) less than 164 bar eliminates the risk of cryohydrates in the production system. This is achievable if the choke size greater than $12 \mathrm{~mm}$ is used.

\section{References}

1. C. Strătulă, Purificarea Gazelor (Editura Științifică și Enciclopedică, București, 1984).

2. N. Pușcoiu, Exploatarea Zăcămintelor de Gaze, partea a doua - Extracția gazelor, (Editura Tehnică, București, 1970).

3. J. Caroll, Natural Gas Hydrates - A guide for Engineers (Elsevier Science and Technology Books, 2002).

4. D. Grigorescu, M. Iung, Deshidratarea Gazelor Naturale (Editura Tehnică, București, 1971). 
5. M. Saeid, A.P. William, Y.M. John, Handbook of Natural Gas Transmission and Processing - Principle and Practices, 3rd Edition (Gulf Professional Publishing, Elsevier, 2015).

6. L. Kohl, C. Risenfleld, Gas Purification (McGraw-Hill Book Company, New York, 1960).

7. Schlumberger, Pipesim Gas Field Production Operation Manual, Workflow Training, (2012). 